\title{
Microstructure and Mechanical Performance of FSWed Joint of T2 Copper and AA 1061
}

\author{
Hongjun $\mathrm{Li}^{1 *}$, Xinchen $\mathrm{Qu}^{1}$, Jian $\mathrm{Gao}^{1}$, Gihad $\operatorname{Karrar}^{2}$, Athanasios Toumpis ${ }^{2}$, \\ Alexander Galloway ${ }^{2}$ \\ ${ }^{1}$ National and Local Joint Engineering Research Center of Reliability Analysis and \\ Testing for Mechanical and Electrical Products, Zhejiang Sci-Tech University, \\ Hangzhou 310018, China \\ ${ }^{2}$ Department of Mechanical \& Aerospace Engineering, University of Strathclyde, \\ Glasgow G1 1XJ, UK \\ *Correspondence: lihongjun@zstu.edu.cn
}

\begin{abstract}
Welding of copper and aluminium has been problematic with tradition fusion method. The friction stir welding (FSW) was employed to butt weld the T2 copper and 1061 aluminum alloy plates. The welding parameters were planned by the orthogonal experiment design method. The samples obtained in experiments were investigated in the aspects of microstructure, tensile strength, fatigue performance and micro-hardness. Sound weld with the best tensile strength and fatigue life was produced under the welding parameters of rotation speed, $1100 \mathrm{rpm}$ and welding speed $50 \mathrm{~mm} / \mathrm{min}$. The tensile strength was $193.16 \mathrm{MPa}, 85 \%$ of the base aluminium material. Three intermetallic compounds (IMC) of $\mathrm{CuAl}, \mathrm{Cu}_{3} \mathrm{Al}$ and $\mathrm{Cu}_{9} \mathrm{Al}_{4}$ were detected at the copper-aluminium interface in XRD analysis.
\end{abstract}

Keywords: friction stir welding, welding parameters, T2 Copper, AA 1061, Microstructure, Mechanical Performance 


\section{Introduction}

Structures with dissimilar metals have shown increasing applications in the industries of electrical engineering, shipping, automotive, aircraft and so on $[1,2]$. The main problem concerning copper-aluminum joint is that the melting points of copper and aluminium are different, as the two materials are not adjacent in the periodic table of the elements. With common welding methods (ultrasonic welding, laser welding, arc welding, etc.), it is prone to form defects of brittle intermetallic compound layers, voids or cracks in the vicinity of interface. Friction Stir Welding (FSW) technology provided a solution avoiding these defects for the reason that it is a solid-state joining process and well suited for non-ferrous metals [3].

The feasibility of joining copper and aluminum by friction stir welding has been proved with experimental studies. In 2003, Lee and Jung [4] obtained a sound joint of dissimilar $\mathrm{Cu} / 6061 \mathrm{Al}$ alloy by varying tool rotations, welding speeds and tool deviations from the centerline. The weld had a dynamic recrystallized structure of each material, intermetallic compound and unpredictable oxides. Ouyang et al. [5] studied the microstructural evolution in the FSWed 6061 (T6-temper condition) to copper. Copper and aluminum metal elements easily produce intermetallic compounds with high brittleness, high resistance and low strength when the welding temperature exceeds $120^{\circ} \mathrm{C}$. The weld consisted of several intermetallic compounds such as $\mathrm{CuAl}_{2}$, $\mathrm{CuAl}$, and $\mathrm{Cu}_{9} \mathrm{Al}_{4}$. In copper adjacent to the bottom of the weld, a mixed layer of $\mathrm{Cu}_{9} \mathrm{Al}_{4}$ and the deformed $\mathrm{Cu}$ solid solution showed an intercalated microstructure or vortex flow pattern. Fotoohi et al. [6] investigated butt joining of A15083 to pure copper. Intermetallic compounds $\mathrm{Cu}_{9} \mathrm{Al}_{4}$ and $\mathrm{CuAl}_{2}$, were detected in the stir zone. Similar results were reported in [7-11]. However, Srujan Manohar and Mahadevan [12] found no intermetallic compound welding thin T6-6061 and pure-copper sheets of $0.8 \mathrm{~mm}$ thickness. Instead, alternate-layers of aluminium and copper mixture existed at the interface. Murr et al. [13] tested the FSW joint of 0.6mm thick copper and 6061 aluminum alloy and found no formation of brittle intermetallic compounds. Xue et al. [14] welded 1060 aluminum alloy and pure copper by shifting the tool to the aluminum 
side and successfully. A good metallurgical bond was created at the aluminum-copper interface, forming a thin, continuous and uniform aluminum-copper intermetallic compound layer. The tensile strength higher than $210 \mathrm{MPa}$ was achieved and fracture occurred in the heat-affected zone of the aluminum side. At rotation speeds higher than $600 \mathrm{rpm}$, stacking layered structure around the $\mathrm{Al}-\mathrm{Cu}$ interface resulting in the poor mechanical properties [15]. Kumar et al. [16] found that the maximum strength of butt welding of AA6061-T6 and pure copper reached $181 \mathrm{MPa}$ (79\% of the base copper).

As to the fatigue performance, the fatigue crack initiation process accounts for about $90 \%$ of the total life [17]. The existence of defects greatly accelerates the crack initiation process. Defect is one of the main causes of the sudden decline in the life of welded joints. In practical applications, fatigue failure of parts accounts for $50 \%$ to $90 \%$ of the total failures [18]. de Oliveira Miranda et al. [19] combined the experimental results and numerical models of 50XX and 60XX series aluminum alloys to compare the fatigue life with the IIW recommended curve, and established a fracture mechanics model to determine the effect of parameters on the fatigue properties of materials. Li et al. [20] concluded that the process parameters, stress ratio, environment and residual stress have great impact on fatigue performance.

It can be seen from the literature that the fatigue life data for dissimilar joint of Al$\mathrm{Cu}$ in the literature are scarce. In this paper, friction stir welding technology was used to butt weld T2 Copper and AA 1061 plates. Various process parameters (tool rotation speeds and weld speeds) were tested, but the tool still pointed to the joining line, rather deviating to either side (suggested in [4] and [14]). The microstructure, tensile strength, hardness and fatigue life were investigated.

\section{Materials and Methods}

\subsection{Friction stir welding experiment}

In the experiment, the plates, T2 copper and 1061 aluminum alloy, were cut into the size of $150 \mathrm{~mm} \times 50 \mathrm{~mm} \times 3 \mathrm{~mm}$. The aluminium was placed on the advancing side. Since welding of copper and aluminum materials requires higher temperature resistant, wear resistant and higher hardness tool materials compared with aluminum-aluminum 
welding, the W6Mo5Cr4V2 (M2) high-speed steel was selected to make the tool. The shape and main sizes of the tool used in this paper are shown in Figure 1.

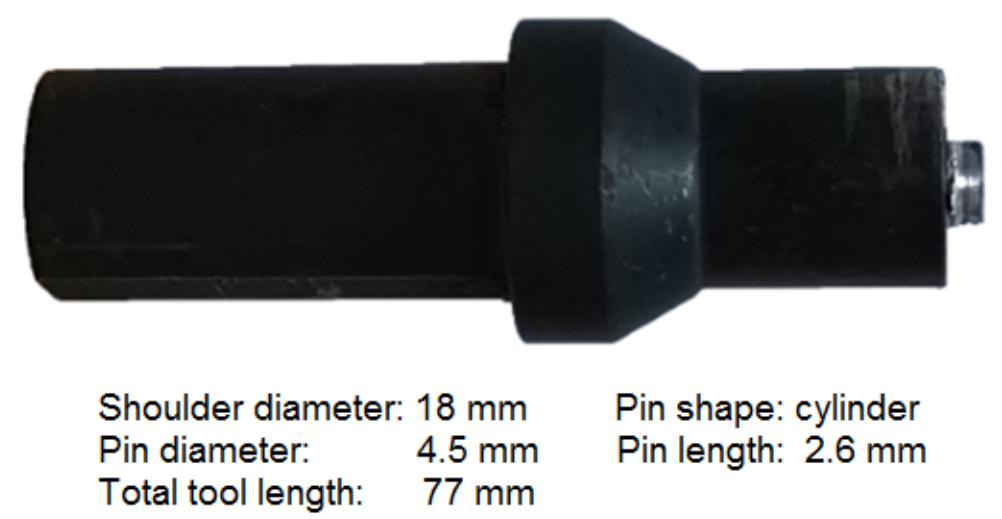

Figure 1 FSW tool shape and geometry

The process parameters have a direct impact on the quality of welded joints [7]. Rotation speed, welding speed, plunge depth and tilt angle are the main parameters. The orthogonal experiment design method was implemented to reduce the number of experiments. Based on trial tests, three rotation speeds, $1000 \mathrm{rpm}, 1100 \mathrm{rpm}, 1200 \mathrm{rpm}$ and three welding speeds, $40 \mathrm{~mm} / \mathrm{min}, 50 \mathrm{~mm} / \mathrm{min}, 60 \mathrm{~mm} / \mathrm{min}$ were chosen to study their effect on the weld microstructure and mechanical performance. The tilt angle and tool shoulder plunge depth were kept constant at $2.7^{\circ}$ and $0.3 \mathrm{~mm}$, respectively. The combinations of process parameters for each test are given in Table 1.

Table 1 Process parameters for each test

\begin{tabular}{cccc}
\hline Test No. & $\begin{array}{c}\text { Rotation speed, } \\
\omega(\mathrm{rpm})\end{array}$ & $\begin{array}{c}\text { Welding speed, } \\
(\mathrm{mm} / \mathrm{min})\end{array}$ & $\omega / \nu$ \\
\hline 1 & 1000 & 40 & 25 \\
2 & 1000 & 50 & 20 \\
3 & 1000 & 60 & 16.67 \\
4 & 1100 & 40 & 27.5 \\
5 & 1100 & 50 & 22 \\
6 & 1100 & 60 & 18.33 \\
7 & 1200 & 40 & 30 \\
8 & 1200 & 50 & 24 \\
9 & 1200 & 60 & 20 \\
\hline
\end{tabular}




\subsection{Microscopy}

When FSW processes finished, the jointed plates were subjected to natural aging treatment. The samples were sectioned from each plate perpendicular to the direction of welding. The metallographic samples had a size of $30 \mathrm{~mm} \times 10 \mathrm{~mm} \times 3 \mathrm{~mm}$ and were mounted, ground and mechanically polished. For the aluminium side of the sample, electrolytic polishing with a perchloric acid and ethanol solution was performed to remove the slightly disturbed metal during mechanical polishing. The $20 \%$ hydrofluoric acid solution was then smeared on the sample surface to highlight the structure. For the copper side, $36 \%$ phosphoric acid aqueous solution was used in electrolytic polishing. The microstructure of the sample was observed with an optical microscope and a scanning electron microscope (SEM). XRD was used to detect the presence of intermetallic compounds (IMC) at the $\mathrm{Cu}-\mathrm{Al}$ interface. The scanning range $2 \theta$ was $20^{\circ} \sim 80^{\circ}$, the angular resolution was $0.02^{\circ}$, the scanning speed was $4 \% \mathrm{~min}$, and the wavelength was $0.15 \mathrm{~nm}$.

\subsection{Mechanical performance testing}

The micro-hardness measurement was carried out on the cross-section of the weld. The indentation positions were arranged in three rows, of which the distances to top surface were $0.5 \mathrm{~mm}, 1.5 \mathrm{~mm}$, and $2.5 \mathrm{~mm}$, respectively. The distance of neighboring points in lateral direction was $0.5 \mathrm{~mm}$, as shown in Figure 2. The geometry and dimensions of the tensile specimens were shown in Figure 3. Prior to the tensile test, the samples were polished to eliminate scratches left by wire cutting. The tensile machine exerted the tensile force on the sample at a speed of $2 \mathrm{~mm} / \mathrm{min}$. After fracture, the fracture surface was scanned with JSM-5610LV SEM. The geometry and dimensions of the fatigue specimens were shown in Figure 4.The fatigue test was performed on Electro Plus E3000 Instron fatigue test machine. The applied stress ratio was 0.6. 
Figure 2 Hardness measurement positions

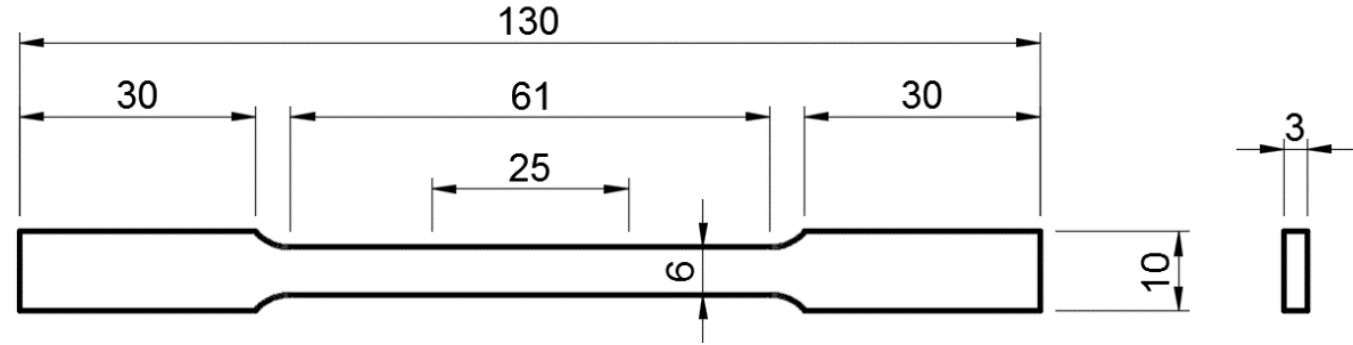

Figure 3 Geometry of tensile specimen, unit: $\mathrm{mm}$

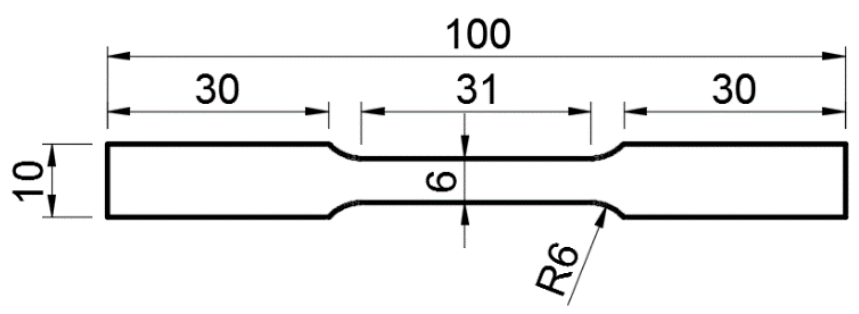

Figure 4 Geometry of fatigue test specimen, unit: $\mathrm{mm}$

\section{Results and Discussion}

\subsection{Weld morphology and microstructure}

The morphology of the welding area was significantly affected by welding parameters. It can be seen from the Figure 5 that there were intermittent groove defects in tests \# 2, \# 3, \# 6, \# 8 and \# 9. The tests \# 1 and \# 5 produced relatively smooth weld surfaces, this can also be reflected from the recorded axial loads of tests \# 1 and \# 5, Figure $6(\mathrm{a}, \mathrm{c})$. During the steady welding process (e.g. from 100s to 200s), the load values were more stable than those in the tests with defects, Figure 6 (b, d). Excessive heat input can also cause defects. Test \#7 had the highest ratio of rotation speed to welding speed, and the highest heat input resulting in the worst weld morphology. There was a crack along the welding line and material flash was scattered irregularly. From the axial load history, Figure 6 (d), it can be seen that the applied force gradually increased with the time, and the maximum force was far higher than those in other tests. The surface of the weld area was covered by silver-white color metals with slight burrs, 
indicating aluminum was stirred and squeezed by the tool to the surface of the plates. This was related to the fact that the density and melting point of aluminum are smaller and the flowability is better than that of copper. To examine the inside of the weld, the sample \# 4 was cut across the weld. The hole defect was found at the copper-aluminium interface, a cross-section view was shown in Figure 7. Due to the rotation of tool, the dissimilar materials were stirred into each other, and the interface changed from a straight line into zigzag lines.

Figure 8 presents the cross-section view of the welded plate in test \# 5, no defect was found. There was a clear boundary between the copper and aluminium parts shown in different colors. By observing two enlarged zones A and B, the top layer of the stirring area was aluminum dominate. A small copper slice in the upper area entered into the aluminum side, as indicated in zone A. In zone B, a large amount of aluminum was forced into the copper side. In the further enlarged views, judging from material colors, small copper particles were distributed in those aluminum materials, forming aluminium matrix metal composite. This was also proved by the EDS results shown in Table 2. The detection position was illustrated in Figure 9. A certain amount of copper was detected in all the five positions, among which the positions 4 and 5 were inside the aluminate dominate region. From the enlarged view of positions 1-3 along the interface of aluminium dominate region and copper bulk region, the mechanical locking can be noticed with small hook structures, implying the good bonding formed in the weld. 


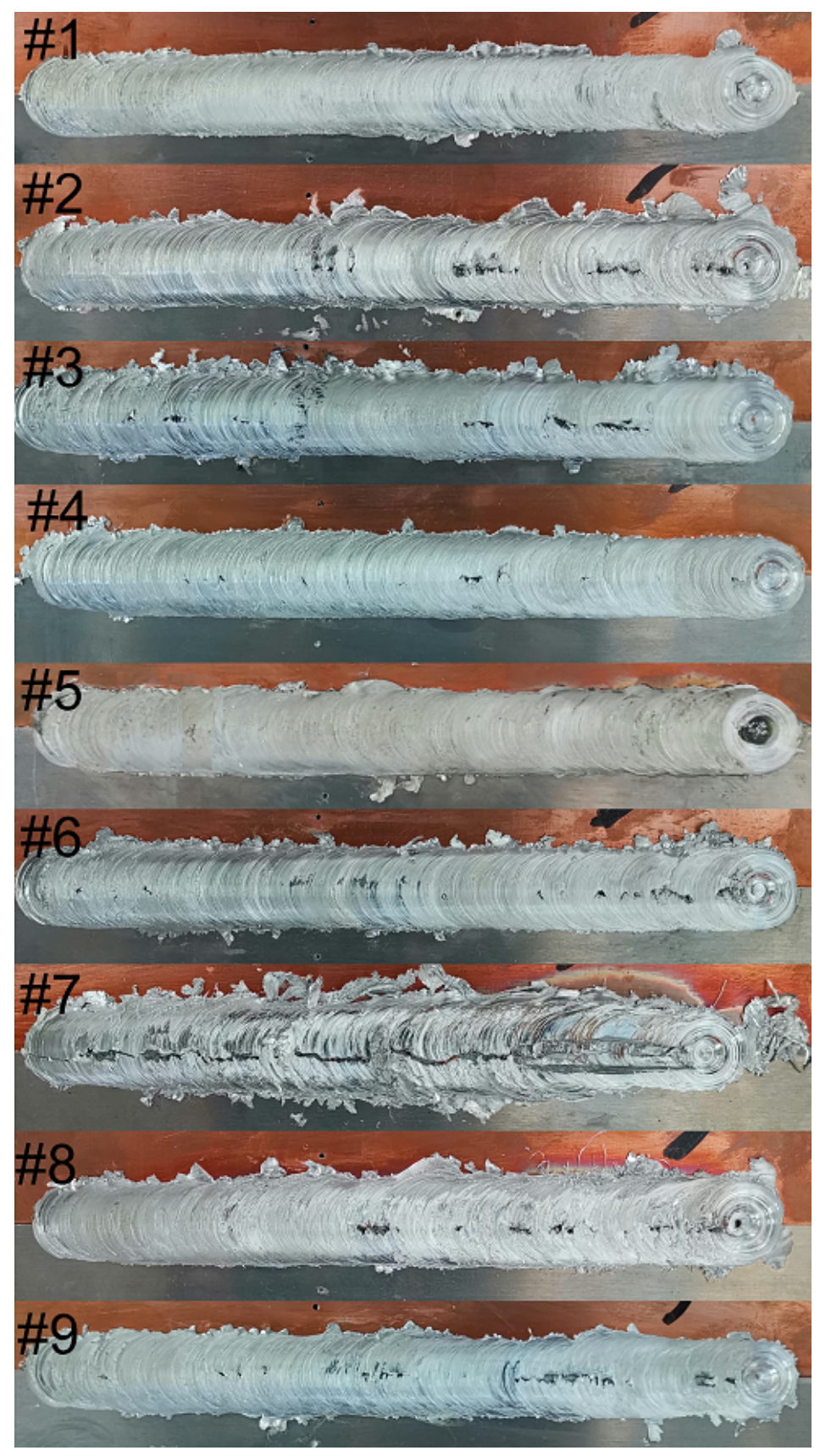

Figure 5 Weld appearance for all the tests 


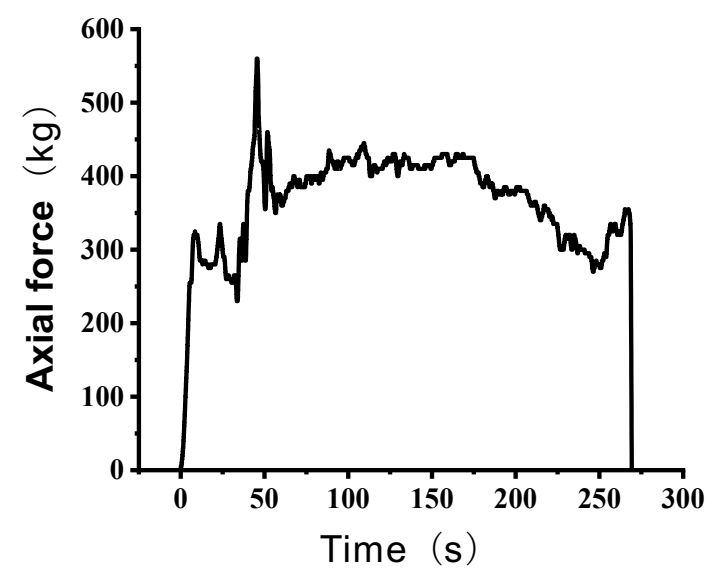

(a)

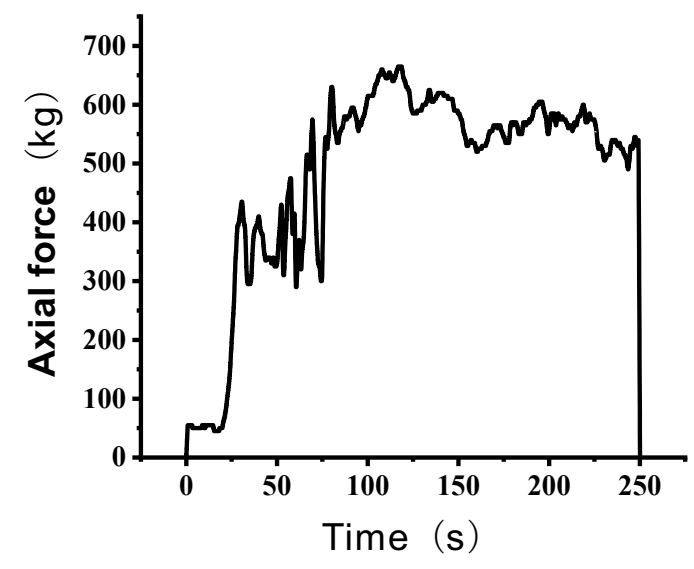

(c)

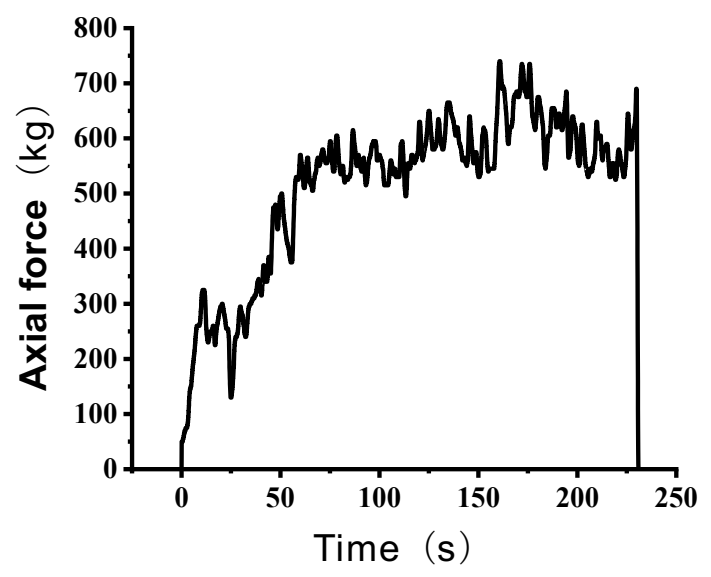

(b)

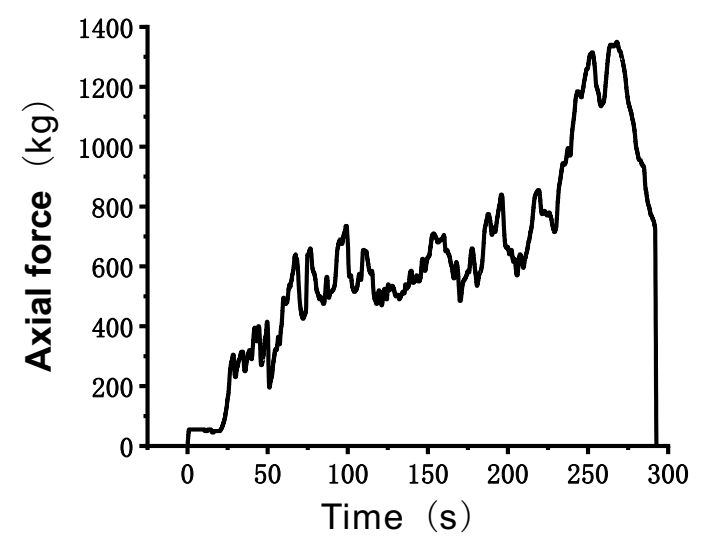

(d)

Figure 6 Axial force histories: (a) test \# 1; (b) test \# 2; (c) test \# 5; (d) test \# 7

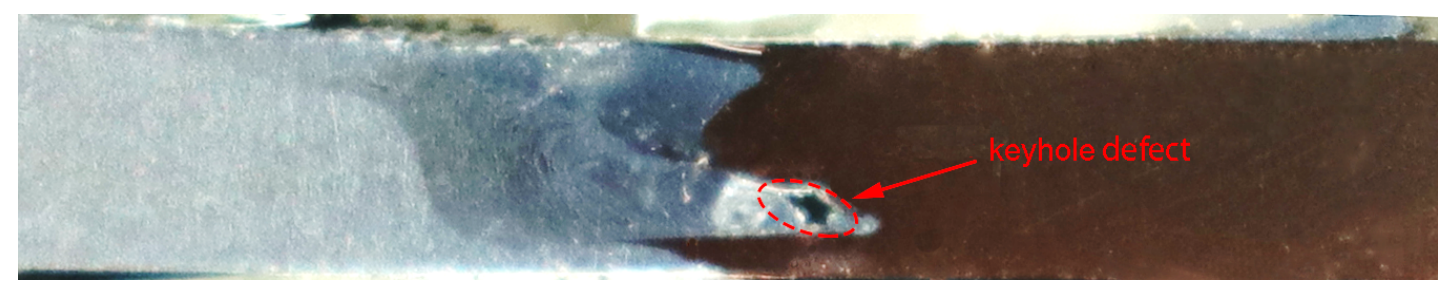

Figure 7 The weld cross section of the sample in test \# 4 


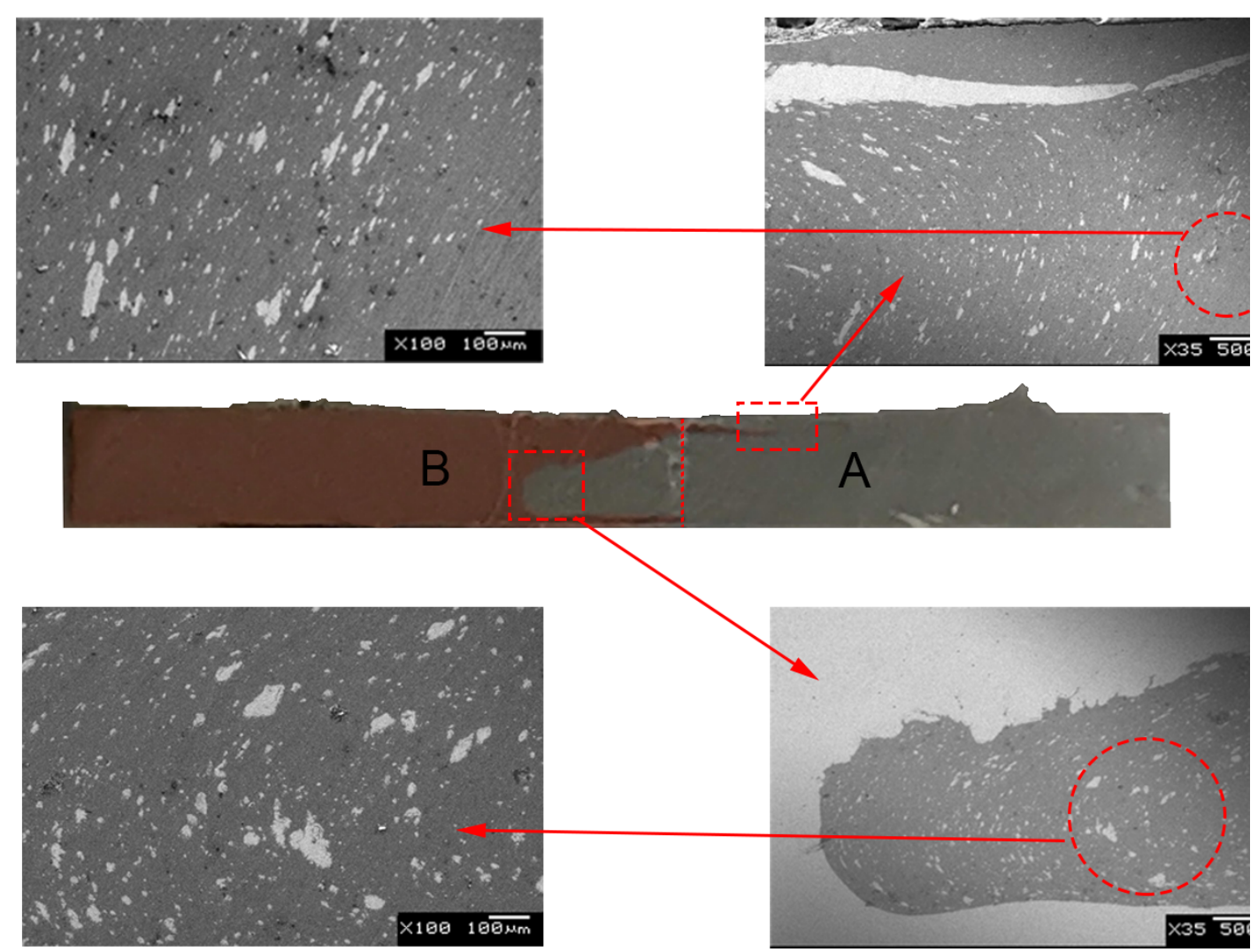

Figure 8 Optical microscope observation of the weld cross section

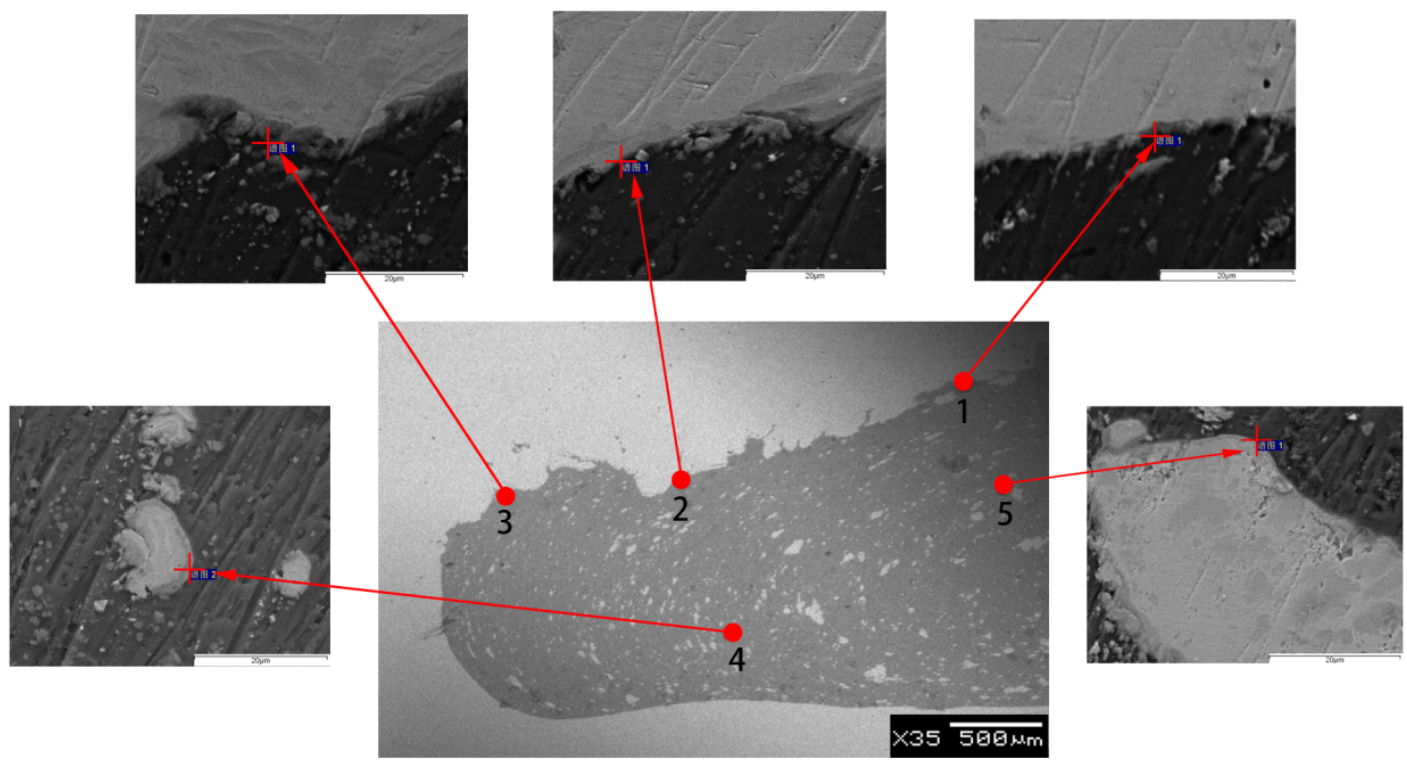

Figure 9 EDS test location 
Table 2 EDS test results

\begin{tabular}{ccc}
\hline Positions & $\mathrm{Al}(\mathrm{at} \%)$ & $\mathrm{Cu}(\mathrm{at} \%)$ \\
\hline 1 & 89.25 & 10.75 \\
2 & 86.91 & 13.09 \\
3 & 96.40 & 3.60 \\
4 & 84.34 & 15.66 \\
5 & 67.25 & 32.75 \\
\hline
\end{tabular}

Due to the high temperature and intense plastic deformation in the mixing zone of aluminium and copper, the intermetallic compounds (IMC) can be easily produced $[5,14]$. The X-ray diffraction (XRD) scan analysis was then performed to analyze the material components in the weld area. In current study, depending on the welding parameters, three intermetallic compounds of $\mathrm{CuAl}, \mathrm{Cu}_{3} \mathrm{Al}$ and $\mathrm{Cu}_{9} \mathrm{Al}_{4}$ could be produced. Sample \# 4 had two IMCs, $\mathrm{CuAl}$ and $\mathrm{Cu}_{3} \mathrm{Al}$, but samples \#5 and \# 6 had only one $\mathrm{IMC}, \mathrm{Cu}_{9} \mathrm{Al}_{4}$ and $\mathrm{Cu}_{3} \mathrm{Al}$, respectively. The detailed $\mathrm{XRD}$ results for samples \#5 were provided in Figure 10. The FSW parameters in the three tests had same rotation speed, but different welding speed. There was no clear trend of IMC formation with the change of welding speed. Among the three samples, only sample \#5 had no defect. $\mathrm{Cu}_{9} \mathrm{Al}_{4}$ was frequently reported in the literature $[7-11,14]$.

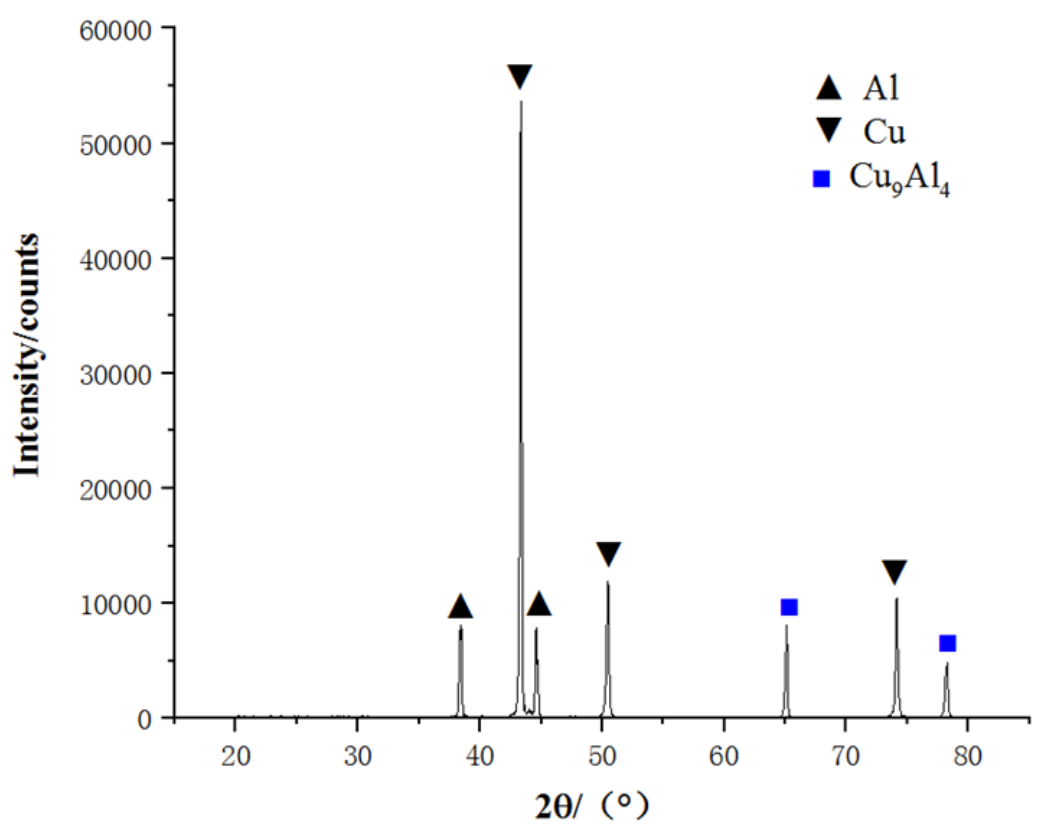

Figure10 XRD scan results for sample \# 5 


\subsection{Tensile strength}

Tensile strength is an important indicator in the assessment of the weld mechanical performance. Table 3 presents the tensile properties of joints under different parameters. The welds in test $\# 5$ showed the highest tensile strength. This was consistent with the microstructure analysis that the sample \# 5 had no defect. The average tensile strength of specimens in test $\# 5$ was $193.16 \mathrm{MPa}, 85 \%$ of the base aluminium material. For a given significance level $\alpha=0.1$, the critical $F_{0.1}$ value is 4.32. The calculated $F_{A}$ and $F_{B}$ were 14.214 and 5.802, respectively, as illustrated in Table 4. Therefore, factor A, rotation speed, had a very significant influence and factor B, welding speed, had a significant influence on the tensile strength.

Table 3 Tensile test results and analysis

\begin{tabular}{|c|c|c|c|c|c|c|}
\hline \multirow{3}{*}{$\begin{array}{l}\text { FSW } \\
\text { Test }\end{array}$} & \multicolumn{2}{|c|}{ Parameter } & & \multirow{3}{*}{ Specimen a } & \multirow{3}{*}{ Specimen b } & \multirow{3}{*}{$Y_{i}$} \\
\hline & $\mathrm{A}$ & B & & & & \\
\hline & Rotation speed & Welding speed & & & & \\
\hline 1 & 1 & 1 & 1 & 137.73 & 168.25 & 152.99 \\
\hline 2 & 1 & 2 & 2 & 86.45 & 24.02 & 55.235 \\
\hline 3 & 1 & 3 & 3 & 81.08 & 127.33 & 104.205 \\
\hline 4 & 2 & 1 & 2 & 109.92 & 115.07 & 112.495 \\
\hline 5 & 2 & 2 & 3 & 196.58 & 189.73 & 193.155 \\
\hline 6 & 2 & 3 & 1 & 128.97 & 156.90 & 142.935 \\
\hline 7 & 3 & 1 & 3 & 0.00 & 0.00 & 0 \\
\hline 8 & 3 & 2 & 1 & 70.33 & 90.87 & 80.60 \\
\hline 9 & 3 & 3 & 2 & 134.83 & 176.50 & 155.665 \\
\hline
\end{tabular}

Table 4 Analysis of variance for means of tensile strength

\begin{tabular}{llllll}
\hline Source & $\begin{array}{l}\text { Sum of squared } \\
\text { deviations }\end{array}$ & $\begin{array}{l}\text { Degrees } \\
\text { of } \\
\text { freedom }\end{array}$ & $\begin{array}{l}\text { Sum of squared mean } \\
\text { deviations }\end{array}$ & F & Saliency \\
\hline A & 7713.23 & 2 & 3856.615 & 14.214 & $\begin{array}{l}\text { Very } \\
\text { significant }\end{array}$ \\
B & 3148.70 & 2 & 1574.35 & 5.802 & Significantly \\
Error & 1085.30 & 4 & 271.325 & & \\
sum & 11947.23 & 8 & & & \\
\hline
\end{tabular}


The fracture of the tensile specimen under the optimum welding parameters occurred at the aluminium side of the weld. The bonding interface of copper and aluminium remained sound and the tensile strength was purely dependent on the aluminium material in the heat affected zone and thermo-mechanically affected zone. The fracture surface analysis was performed using JSM-5610LV5610LV scanning electron microscope. The SEM images with two different magnifications were shown in Figure 11. The fracture surface was characterized by a large number of dimples, which means the specimen experienced a ductile fracture. Dimples are traces left by micro-void coalescence during fracture. In general, the ductile fracture can be divided into three phases: micro-void nucleation, micro-void expansion and micro-void coalescence. When loaded with external force, the specimen exhibited plastic deformation and necking. It can also be seen that the dimples had different sizes (diameter and depth). The larger size indicated larger grains, larger precipitates and higher shear ductility [21].
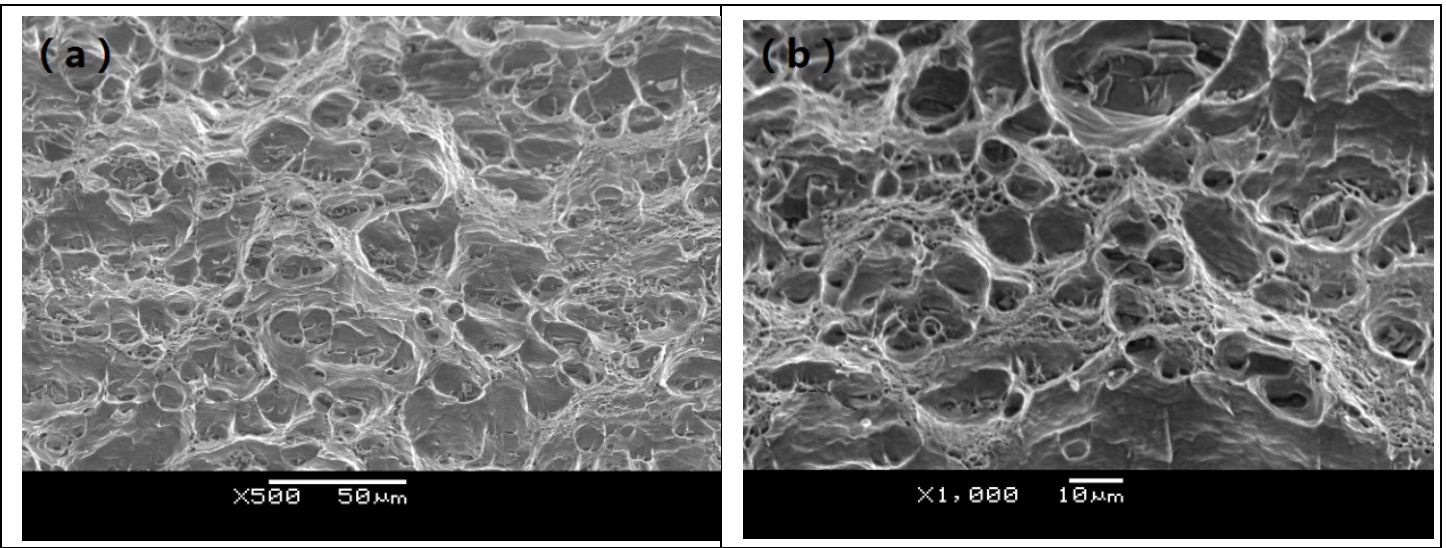

Fig.11 SEM image of the tensile specimen of FSW test \# 5

\subsection{Fatigue performance}

The fatigue test results for the FSW weld samples were summarized in Table 5. For the samples produced at high rotation speed, as of result of defects, the fracture occurred at very low loading cycle, thus, the results were not recorded in the table. Comparing the fatigue lives, the sample from the FSW test \# 5 had the highest value, 
consistent with the tensile strength results. The fracture location occurred in the weld zone along the welding line. The copper-aluminum interface remained in close contact and not damaged by the fracture surface. The fracture surface almost stayed vertical and perpendicular to the direction of applied load, rather than following the zigzagged copper-aluminum interface, indicating the excellent bonding performance at the interface.

Table 5 Fatigue test results

\begin{tabular}{cccc}
\hline $\begin{array}{c}\text { FSW } \\
\text { Test }\end{array}$ & rotational speed(rpm) & Welding speed $(\mathrm{mm} / \mathrm{min})$ & Fatigue life \\
\hline 1 & 1000 & 40 & $2 \times 10^{3}$ \\
2 & 1000 & 50 & $1 \times 10^{5}$ \\
3 & 1000 & 60 & $3 \times 10^{4}$ \\
4 & 1100 & 40 & $2.1 \times 10^{4}$ \\
5 & 1100 & 50 & $7.5 \times 10^{5}$ \\
6 & 1100 & 60 & $6.2 \times 10^{5}$ \\
7 & 1200 & 40 & - \\
8 & 1200 & 50 & - \\
9 & 1200 & 60 & - \\
\hline
\end{tabular}

\subsection{Micro-hardness Analysis}

The micro-hardness of cross section for sample \# 5 was measured at 135 points in three rows, illustrated in Figure 2. The distribution of hardness was plotted in Figure 12. It can be seen that the average hardness on the retreating side (copper plate) was much higher than that on the advancing side (aluminum plate). But in the nugget zone $(-2.25 \sim 2.25 \mathrm{~mm})$, the hardness was similar on both sides. The hardness was slightly higher than that of the copper side, mainly due to the strong plastic deformation of the grains. The material in the nugget zone had undergone a dynamic recrystallization process, and the grain size was refined, leading to the increase of hardness. The top row points gave higher hardness around pin region than the middle and bottom row points due to the intense friction and stirring by the tool. In the regions around $-5 \mathrm{~mm}$ and $5 \mathrm{~mm}$, the hardness dropped because the heat affected zone and the thermo-mechanically affected zone experienced the influence of thermal 
cycling. The grain size was coarsened and the hardness decreased. Towards the parent material, the effect of thermal cycling declined, thus the hardness increased.

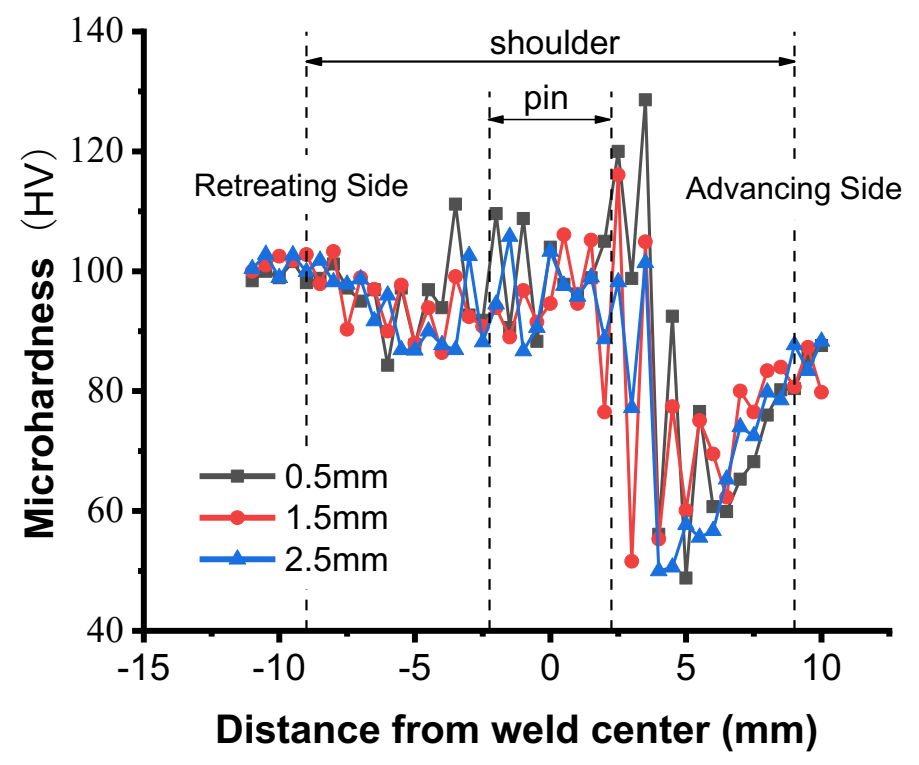

Figure 12 Micro-hardness distribution of $\mathrm{Cu}-\mathrm{Al}$ welded joints

\section{Conclusion}

The $3 \mathrm{~mm}$ thick plates of T2 copper and 1061 aluminum alloy was successfully butt welded by friction stir welding technology. The microstructure and mechanical performance of the weld were studied by means of optical microscope observation, EDS, XRD, tensile test, SEM and fatigue test. The following conclusions have been reached based on the obtained results.

(1) The sound weld with no defect can be produced under the selected welding parameters. There is no need to deviate the tool from the weld center line.

(2) The rotation speed has a very significant influence on the formation of the weld. Higher rotation speed causes higher heat input, worse weld morphology and more defects. Lower rotation speed leads to insufficient heat input and weaker bonding at the copper aluminium interface.

(3) In the weld nugget, small copper particles were distributed into the aluminium bulk, forming aluminium matrix composite. In the cross-section view of the weld, a zigzag shaped interface between aluminium dominate region and copper bulk was generated. 
(4) Three intermetallic compounds of $\mathrm{CuAl}, \mathrm{Cu}_{3} \mathrm{Al}$ and $\mathrm{Cu}_{9} \mathrm{Al}_{4}$ were detected at the interface of aluminium and copper. $\mathrm{Cu}_{9} \mathrm{Al}_{4}$ only existed in the weld without defects, i.e. $\mathrm{Cu}_{9} \mathrm{Al}_{4}$ can only be created at certain temperature.

(5) For the weld produced with optimum welding parameters, the tensile strength achieved $85 \%$ of the 1061 aluminum alloy parent plate. The fracture surface showed a typical ductile fracture. The tensile fracture location occurred on the aluminium side close to the transition region of heat affected zone and thermomechanically affected zone.

(6) There were mainly two kinds of defects, grooves and holes. The existence of defects seriously decreased the fatigue life.

\section{References}

[1] Al-Roubaiy A O, Nabat S M, Batako A D L, Experimental and theoretical analysis of friction stir welding of $\mathrm{Al}-\mathrm{Cu}$ joints. International Journal of Advanced Manufacturing Technology, 2014, 71(9-12):1631-1642.

[2] Fu B, Qin G, Li F, Meng X, Zhang, J, Wu, C, Friction stir welding process of dissimilar metals of 6061-T6 aluminum alloy to AZ31B magnesium alloy. Journal of Materials Processing Technology, 2015, 218:38-47.

[3] Mishra R S, Ma Z Y, Friction stir welding and processing. Materials Science \& Engineering: R: Reports, 2005, 50(1):1-78.

[4] Lee W B , Jung S B . Void Free Friction Stir Weld Zone of The Dissimilar 6061 Aluminum And Copper Joint By Shifting The Tool Insertion Location. Materials Research Innovations, 2004, 8(2): 93-96.

[5] Ouyang J, Yarrapareddy E, Kovacevic R. Microstructural evolution in the friction stir welded 6061 aluminum alloy (T6-temper condition) to copper. Journal of Materials Processing Technology, 2006, 172(1): 110-122.

[6] Fotoohi Y, Rasaee S, Bisadi H, Zahedi M, Effect of friction stir welding parameters on the mechanical properties and microstructure of the dissimilar Al5083-copper butt joint, Proceedings of the Institution of Mechanical Engineers, Part L: Journal of Materials: Design and Applications, 2014, 228(4): 334-340.

[7] Rzaev, R, Chularis A, Smirnov V, Semyenova L, The Influence of the Friction Stir Welding Parameters on the Formation of Welded Joint of Aluminum and Copper Alloys, Materials Today: Proceedings, 2019, 11(1): 534-542. 
[8] Li G H, Zhou L, Zhou W, Song X, Huang Y, Influence of dwell time on microstructure evolution and mechanical properties of dissimilar friction stir spot welded aluminum-copper metals, Journal of Materials Research and Technology, 2019, 8(3): 2613-2624.

[9] Zhou L, Zhang R X, Li G H, Zhou W L, He W X, Huang Y X, Song X G, Microstructure evolution and mechanical properties of friction stir spot welded dissimilar aluminum-copper joint, Journal of Alloys and Compounds, 2019, 775: 372-382.

[10] Zhou L, Zhang R X, Li G H, Zhou W L, Huang Y X, Song X G, Effect of pin profile on microstructure and mechanical properties of friction stir spot welded $\mathrm{Al}-\mathrm{Cu}$ dissimilar metals[J]. Journal of Manufacturing Processes, 2018, 36:1-9.

[11] Zhang W, Shen Y, Yan Y, Guo R, Dissimilar friction stir welding of $6061 \mathrm{Al}$ to T2 pure $\mathrm{Cu}$ adopting tooth-shaped joint configuration: Microstructure and mechanical properties, Materials Science \& Engineering, 2017, 690:355-364.

[12] Srujan Manohar M V N, Mahadevan K, Prediction on mechanical and microstructural behaviour of friction stir welded thin gauge aluminium-copper sheets, Materials Today: Proceedings, 2020, in press.

[13] Murr L E, Li Y, Flores R D, et al. Intercalation vortices and related microstructural features in the friction-stir welding of dissimilar metals. Materials Research Innovations, 1998, 2(3): $150-163$.

[14] Xue P, Xiao B L, Ni D R, Ma Z Y, Enhanced mechanical properties of friction stir welded dissimilar Al-Cu joint by intermetallic compounds. Materials science and engineering: A, 2010, 527(21-22): 5723-5727.

[15] Xue P, Ni D R, Wang D, Xiao B L, Ma Z Y, Effect of friction stir welding parameters on the microstructure and mechanical properties of the dissimilar $\mathrm{Al}-\mathrm{Cu}$ joints. Materials science and engineering: A, 2011, 528(13-14): 4683-4689.

[16] Kumar N, Dhuria G K, Singh R. Evaluation of tensile strength in friction stir welded aluminum alloy 6101-T6 and commercially pure copper joints. Materials Today: Proceedings, 2018, 5(9): 19230-19236.

[17] Chakraborty D, PAL T K. High-cycle fatigue behavior of friction stir butt welded 6061 aluminium alloy. Transactions of Nonferrous Metals Society of China 2014; 4(3): 648-656.

[18] Susmel L, Hattingh D G, James M N, et al. Multiaxial fatigue assessment of friction stir welded tubular joints of Al 6082-T6[J]. International Journal of Fatigue, 2017, 101: 282-296.

[19] de Oliveira Miranda A C, Gerlich A, Walbridge S. Aluminum friction stir welds: Review of fatigue parameter data and probabilistic fracture mechanics analysis $[\mathrm{J}]$. Engineering Fracture Mechanics, 2015, 147: 243-260.

[20] Li H, Gao J, Li Q. Fatigue of Friction Stir Welded Aluminum Alloy Joints: A Review[J]. Applied Sciences, 2018, 8(12).

[21] Dada O J, Fracture mechanics and mechanical behaviour in AA5083-H111 friction stir welds, Scientific African, 2020, 8:e0265. 